\title{
Factors affecting clinical pregnancy rates after IUI for the treatment of unexplained infertility and mild male subfertility
}

\author{
Melahat Atasever', Müberra Namlı Kalem², Şafak Hatırnaz³, Ebru Hatırnaz³, Ziya Kalem , Zeynep Kalaylığlı ${ }^{5}$ \\ ${ }^{1}$ Department of Obstetrics and Gynecology, Giresun University School of Medicine, Giresun, Turkey \\ ${ }^{2}$ Department of Obstetrics and Gynecology, Turgut Özal University School of Medicine, Ankara, Turkey \\ ${ }^{3}$ Clinart IVF Center, Giresun, Turkey \\ ${ }^{4}$ Gürgan Clinic IVF Center, Ankara, Turkey \\ ${ }^{5}$ Department of Statistics, Middle East Technical University, Ankara, Turkey
}

\begin{abstract}
Objective: The aim of the present retrospective study was to evaluate intrauterine insemination (IUI) clinical experiences and to define the variables for predicting success.

Material and Methods: The present study was an observational trial performed in a private IVF center on subfertile couples who had applied for treatment between 2002 and 2012, in which the data of 503 IUI cases were retrospectively reviewed. Couples who had been diagnosed with unexplained and mild male subfertility were included. The primary outcome measure was the clinical pregnancy rate in an attempt to form a predictive model for the odds of a clinical pregnancy. Recorded parameters were used to determine the prediction model.

Results: Utilizing univariate logistic regression analysis, clinical pregnancy was positively associated with the duration of infertility $(\mathrm{OR}=1.09$, $p=0.089)$, secondary infertility $(O R=1.77, p=0.050)$, and +4 sperm motility after preparation $(O R=1.03, p=0.091)$. Following an adjustment analysis involving a multivariate logistic regression, clinical pregnancy was still found to positively associate with secondary infertility $(\mathrm{OR}=2.51$, $\mathrm{p}=0.008)$.

Conclusion: IUI success in secondary infertile couples who were in the unexplained infertility and mild male subfertility groups was higher than that in primary infertile couples, and the chances of pregnancy increased as sperm numbers with +4 motility increased. It is difficult to concomitantly evaluate all these parameters and to determine a predictive parameter in IUI independent from other factors. (J Turk Ger Gynecol Assoc 2016; 17: 134-8)
\end{abstract}

Keywords: Intrauterine insemination, unexplained infertility, male subfertility

Received: 1 April, 2016 Accepted: 25 July, 2016

\section{Introduction}

Subfertility is defined as the inability to conceive, despite regular sexual intercourse over a period of 12 months, and it affects $10 \%$ of couples who wish to have babies. Intrauterine insemination (IUI) is accepted as the first-line treatment for unexplained infertility and mild male factor subfertility (1-3).

In the literature, many factors affecting pregnancy rates following IUI have been reported. For instance, there are many studies related to age (4), the ovarian reserve of females (5) and sperm parameters in males (6), and the duration and type of infertility (7), which are pre-cycle parameters. Furthermore, the effects of cyclic parameters, such as selected ovulation induction protocols and the characteristics of the obtained follicles, have been evaluated on IUI outcomes in different studies (8-10). Despite all these studies, there is still no con- sensus on parameters that can predict the chances of clinical pregnancy after IUI.

The aim of the present retrospective study was to evaluate IUI clinical experiences at a private IVF center covering a 10-year period and to define the variables for predicting success.

\section{Material and Methods}

The present study comprised an observational trial performed in a private in vitro fertilization (IVF) center on subfertile couples who had applied for treatment between 2002 and 2012, and in which the data of 503 IUI cases were reviewed retrospectively. Couples with a female $<40$ years of age and a male who had been diagnosed with unexplained and mild male subfertility were included in the study. Couples with failure to conceive for $>12$ months, and with normal sperm param- 
eters, bilateral patent fallopian tubes, and regular menstrual cycles were accepted as cases involving unexplained infertility. Sperm samples that had a concentration above $20 \mathrm{million} / \mathrm{mL}$ according to the World Health Organization 1999 criteria, with type a (fast progressive) or type b (medium progressive) motility rates above 50\%, with normal morphology and above 14\% according to Kruger criteria were accepted as normal $(11,12)$. If the sperms in a sperm analysis did not satisfy the aforementioned reference criteria, but the total motility count (TMC) was above 5 million, then couples were accepted as cases involving mild male subfertility. Data from couples with any already determined causes of infertility, and cycles with ovarian hyperstimulation syndrome (OHSS) were not included in the evaluation.

Ovulation induction was performed in 38 cases, using oral tablets of clomiphene citrate (Klomen; Kocak Farma; İstanbul, Turkey), which were started on Day 5 of the cycle and given at a 100 $\mathrm{mg} /$ day dose for five days. Injectable gonadotropin, $\mathrm{rFSH}$ [follitropin alpha (Gonal F, Serono; İstanbul, Turkey), or follitropin beta (Puregon, MSD; İstanbul, Turkey)] was used in 331 cases, and HMG (Menogon, Ferring; İstanbul, Turkey) in 134 cases. Injectable gonadotropin was used on Day 2 or Day 3 of the cycle at doses of 75-150 units. Follicular developments were followed up with transvaginal USG, and dose adjustments were continued until dominant follicle development (max. dose=300 IU). Ovulation triggering was performed using 10000 IU hCG (Pregnyl, MSD; İstanbul, Turkey). Sperms were prepared using the discontinuous gradient method. Briefly, following liquefaction at room temperature, the semen was overlaid on a $40 \%$ and $80 \%$ PureSperm gradient column and centrifuged at $300 \mathrm{~g}$ for $20 \mathrm{~min}$ followed by washing the sperm pellet at $500 \mathrm{~g}$ in a non-capacitating buffer. A single insemination of $0.4 \mathrm{~mL}$ of sperm suspension per cycle was performed at $36 \mathrm{~h}$ after hCG administration under ultrasound guidance. Serum samples were obtained 14 days after hCG administration for $\beta$ hCG levels.

The primary outcome measure of this study was the clinical pregnancy rate, which was gathered in an attempt to form a predictive model for the odds of a clinical pregnancy, defined as observable cardiac activity via a transvaginal ultrasound above six weeks of gestation in women treated by IUI for subfertility. Recorded parameters of maternal age, paternal age, follicle stimulating hormone (FSH) levels, duration of subfertility, type of female subfertility (primary or secondary), type of male subfertility, method of induction (clomiphene citrate or injectable gonadotropin), number of dominant follicles, measured diameter of dominant follicles on the day of hCG, the number of the total motile sperm count and the number of motile sperm counts, i.e., regarding their speeds, were used to determine the prediction model.

The study was ethically approved by the local ethics committee and the written informed consent of all the participants was obtained.

\section{Statistical analysis}

For all the statistical analysis, R v.3.1.3 for Windows was used. For the missing variables in the FSH levels, a stochastic regression imputation model was formed, using age and the antral follicle count as covariates. Missing FSH data were then imputed, by a adding a random number error term to the predicted FSH values. The error term was generated from a normal distribution with a mean of zero, and a variance equal to the regression variance, to introduce variability in the predicted values. To assess the association of the odds of clinical pregnancy with the covariates, first a set of univariate logistic regression analyses was carried out, in which the odds of clinical pregnancy was modeled on each covariate, separately. Second, a multivariable logistic regression was used to estimate the adjusted odd ratios between the odds of clinical pregnancy and the covariates of interest. Finally, a backward stepwise selection method was used to obtain the most explanatory model for the odds of clinical pregnancy. The ages of the women were included in the model to prevent a confounding effect. To ensure the final model was a good fit to the dataset at hand, a goodness of fit of the final logistic regression model was assessed using the Deviance and Hosmer-Lemeshow tests. The null hypothesis of no difference between the null and fitted model was rejected at a significance level of $10 \%$ according to the Deviance test. $P$ values below 0.10 were considered statistically significant. All the statistical computations, comparisons, and analyses were performed using the Statistical Package for Social Sciences Inc. (SPSS version 15.0 for Windows, SPSS Inc.; IL, USA).

\section{Results}

A total of 47 pregnancies were determined in the 503 IUI cycles enrolled in the study. A pregnancy rate of $9.34 \%$ per cycle was determined, and the conception rates were 3 cases in the clomiphene citrate (CC) group, 12 in the human menopausal gonadotrophin (hMG) group, and 32 in the FSH group (7.8\%, 8.9\%, and $9.6 \%$, respectively).

Basal FSH levels, the ages of the males and females, the type and duration of infertility, and male factor characteristics were taken as the basic pre-cycle parameters. The ovulation induction method, the number of follicles obtained, and the diameter of the dominant follicle were evaluated as cycle characteristics. The correlations between the presence of clinical conception and all of these variables were analyzed.

First, a set of univariate logistic regression analyses was carried out, in which the response variable (odds of clinical pregnancy) was modeled separately on each covariate. Table 1 displays the odds ratio estimates (OR), 95\% and 90\% confidence intervals, and p values resulting from the univariate analyses. Accordingly, clinical pregnancy was positively associated with the duration of infertility $(\mathrm{OR}=1.09, \mathrm{p}=0.089)$, secondary infertility $(\mathrm{OR}=1.77, \mathrm{p}=0.050)$, and +4 sperm motility after preparation $(\mathrm{OR}=1.03, \mathrm{p}=0.091)$.

Second, an adjustment analysis was carried out. Multivariate logistic regression was used to estimate the adjusted OR's between the odds of clinical pregnancy and the covariates of interest. The results of the multivariate analysis are given in Table 2 . Accordingly, clinical pregnancy was positively associated with the secondary infertility $(\mathrm{OR}=2.51, \mathrm{p}=0.008)$.

A backward selection method was employed to obtain the most explanatory model for clinical pregnancy in this study. The ages of the women were included in the model to prevent the pos- 
sibility of a confounding effect. Table 3 displays the coefficient estimates, $p$ values, estimated odds ratios, and their confidence intervals in the resultant model. According to the final model, the odds for clinical pregnancy were 1.84 times higher for the women who had a secondary infertility. Furthermore, a one unit increase in +4 sperm motility creates an increase of 1.03 in the odds of achieving a positive outcome.

\section{Discussion}

In the literature, conception following IUI shows a wide range of gestational variation rates. Actually, the causes of these conflicting results are due to the selected treatment group, diagnostic criteria, the techniques used, the mean age of the selected cohort, the cause of infertility, and the change in treatment success according to the number of treatment cycles. In 1997, Hannoun et al. (13) published a study showing a treatment success of $5 \%$ in a single cycle in a CC+IUI group, and $58.7 \%$ in a controlled ovarian stimulation (COS)+IUI group in three cycles. Guzick et al. (14) retrospectively reviewed 45 published articles about unexplained infertility IUI studies, and the author reported clinical gestation rates of $8.3 \%$ in a CC+IUI group, and $17.1 \%$ in an hMG+IUI group. Goverde et al. (15) reported clinical gestational rates of $7.4 \%$ in a natural cycle IUI group, and $8.7 \%$ in a COS+IUI group. Finally, a European study conducted between 2001 and 2004 found that the pregnancy rate per IUI cycle was between $11.4 \%$ and $12.6 \%$ (16). In our study, the obtained clinical gestation rate was $9.34 \%$ (7.8\% in the CC group, $8.9 \%$ in the hMG group, and $9.6 \%$ in the rFSH group), and it was within the wide range.

Table 1. Univariate models

\begin{tabular}{|l|c|c|c|c|}
\hline Covariate & Coefficient & p & OR & Confidence interval \\
\hline FSH (basal) & 0.024 & 0.557 & 1.025 & $90 \%(0.957,1.097)$ \\
\hline Female's age & -0.006 & 0.827 & 0.994 & $90 \%(0.951,1.039)$ \\
\hline Male's age & -0.033 & 0.230 & 0.967 & $90 \%(0.923,1.012)$ \\
\hline Duration of infertility & 0.083 & $0.089 *$ & 1.086 & $90 \%(1.002,1.177) *$ \\
\hline $\begin{array}{l}\text { Type of infertility } \\
\text { (primary/secondary) }\end{array}$ & 0.572 & $0.050 *$ & 1.772 & $90 \%(1.096,2.865) *$ \\
\hline $\begin{array}{l}\text { Male factor } \\
\text { (normal/subfertile) }\end{array}$ & -0.537 & 0.385 & 0.584 & $90 \%(0.211,1.617)$ \\
\hline $\begin{array}{l}\text { Method of ovulation } \\
\text { induction (CC/FSH/hMG) }\end{array}$ & 0.104 & 0.685 & 1.109 & $90 \%(0.727,1.694)$ \\
\hline Follicle count & 0.145 & 0.519 & 1.155 & $90 \%(0.799,1.671)$ \\
\hline Dominant follicle size & 0.004 & 0.948 & 1.004 & $90 \%(0.913,1.104)$ \\
\hline $\begin{array}{l}\text { Sperm count } \\
\text { (after preparation) }\end{array}$ & 0.001 & 0.517 & 1.001 & $90 \%(0.998,1.005)$ \\
\hline Sperm motility +4 & 0.030 & $0.091 *$ & 1.031 & $90 \%(1.009,1.061) *$ \\
\hline Sperm motility +3 & -0.005 & 0.690 & 0.994 & $90 \%(0.972,1.017)$ \\
\hline Sperm motility +2 & 0.009 & 0.599 & 1.009 & $90 \%(0.981,1.037)$ \\
\hline TPMSC & 0.001 & 0.739 & 1.001 & $90 \%(0.997,1.004)$ \\
\hline prat & & & & \\
\hline
\end{tabular}

*p values less than 0.10 indicate a significant association.

FSH: follicle stimulating hormone; CC: clomiphene citrate; hMG: human menopausal gonadotrophin; TPMSC: total progressive motile sperm count; OD: odds ratio
In the present study, a negative correlation was observed between the female age, basal FSH levels, and clinical gestational rates, but the difference was not statistically significant. In the present study, we also observed that as the infertility duration became longer, the gestation rates also increased. However, in the literature, many studies have indicated that as the age $(5,8$, $17)$ and infertility duration $(7,17,18)$ increase, gestational rates decrease. Also, Ibérico et al. (19) reported in a study published in 2004 that gestational rates in IUI decreased independently of the age through longer infertility durations. Contrary to the literature, the results of our study indicated that, as infertility duration increases, so does the gestational chance, and that no correlation was determined between gestational chance and the female or male ages. These might be explained due to the gestational rates being calculated per treatment cycle instead of per couple in our study. It is possible that, as the infertility duration is increased, the cumulative probability of gestation is increased in couples because of the increased number of IUI cycles.

\section{Table 2. Multivariate model}

\begin{tabular}{|l|c|c|c|c|}
\hline Covariate & Coefficient & Standard error & $\mathbf{z}$ & $\mathbf{p}$ \\
\hline FSH & -0.001 & 0.052 & -0.013 & 0.989 \\
\hline Female's age & 0.002 & 0.043 & 0.040 & 0.968 \\
\hline Male's age & -0.054 & 0.045 & -1.205 & 0.228 \\
\hline Duration of infertility & -0.008 & 0.071 & -0.110 & 0.912 \\
\hline $\begin{array}{l}\text { Type of infertility } \\
\text { (primary/secondary) }\end{array}$ & 0.922 & 0.349 & 2.640 & $0.008^{*}$ \\
\hline $\begin{array}{l}\text { Male factor } \\
\text { (normal/subfertile) }\end{array}$ & -0.727 & 0.669 & -1.087 & 0.277 \\
\hline $\begin{array}{l}\text { Method of ovulation } \\
\text { induction (CC/FSH/hMG) }\end{array}$ & 0.255 & 0.296 & 0.863 & 0.388 \\
\hline Follicle count & 0.191 & 0.240 & 0.793 & 0.427 \\
\hline Dominant follicle size & 0.015 & 0.065 & 0.235 & 0.814 \\
\hline $\begin{array}{l}\text { Sperm count } \\
\text { (after preparation) }\end{array}$ & 0.001 & 0.003 & 0.406 & 0.684 \\
\hline Sperm motility +4 & 0.032 & 0.034 & 0.938 & 0.348 \\
\hline Sperm motility +3 & -0.006 & 0.019 & -0.310 & 0.757 \\
\hline Sperm motility +2 & 0.029 & 0.023 & 1.264 & 0.206 \\
\hline TPMSC & -0.001 & 0.004 & -0.369 & 0.712 \\
\hline $\begin{array}{l}\text { FSH: follicle stimulating hormone; CC: clomiphene citrate; hMG: human meno- } \\
\text { pausal gonadotrophin; TPMSC: total progressive motile sperm count }\end{array}$ \\
\hline
\end{tabular}

Table 3. Final model

\begin{tabular}{|c|c|c|c|c|}
\hline Covariate & Coefficient & $\mathbf{p}$ & OR & CI \\
\hline Female's age & -0.021 & 0.462 & 0.979 & $90 \%(0.932,1.027)$ \\
\hline $\begin{array}{l}\text { Type of infertility } \\
\text { (primary/secondary) }\end{array}$ & 0.610 & $0.049 *$ & 1.841 & $90 \%(1.104,3.072) *$ \\
\hline Sperm motility +4 & 0.029 & $0.105^{*}$ & 1.029 & $90 \%(0.999,1.061) *$ \\
\hline $\begin{array}{l}\text { *Hosmer-Lemeshow te } \\
\text { Deviance test, } p=0.089 . \\
\text { OR: odds ratio; } \mathrm{Cl} \text { : confic }\end{array}$ & $\begin{array}{l}\mathrm{st}, \mathrm{p}=0.414 \text {. } \\
\text { dence interval }\end{array}$ & & & \\
\hline
\end{tabular}


In secondary infertility, it was observed that clinical pregnancy rates were 1.84-fold higher than in primary infertility. There are many studies in the literature supporting this data (20-22). However, contradictory conclusions have also been reported. Ibérico et al. (19) and Dorjpurev et al. (23) proposed that infertility type (primary or secondary) did not affect gestational rates $(19,23)$. In the statistical analysis of our cycle data, no statistically significant correlation was shown between the ovulation induction method and the clinical pregnancy rates following IUI. It has been shown in many studies in the literature that the use of FSH and hMG is superior to CC use (24-27). Although we observed that gestational rates were low in the $\mathrm{CC}$ group, we could not show the difference due to the small sample size. There was no difference between the FSH and hMG groups, which is a finding consistent with the literature. There are many studies in the literature reporting that the gonadotropin type affected $(28,29)$ or did not affect (30-32) treatment success rates.

No statistically significant effect was observed between the other examined cycle parameters, the number of obtained follicles, the dominant follicle diameter, and clinical gestation rates. Van Rumste et al. (33) reported that multi-follicular development in IUI did not improve the chances of pregnancy, but rather increased only the number of multiple gestation possibilities. In the meta-analysis containing 11599 cycles, van Rumste (34) reported that the development of two follicles increased the gestation chance more than that with one follicle development, but the development of a higher numbers of follicles did not increase the chances of pregnancy (34). In the same study, van Rumste reported also that the diameter of the dominant follicle did not have a high predictivity. However, Ibérico reported that if the diameter of the dominant follicle was $>20 \mathrm{~mm}$, then the pregnancy rates increased (19) accordingly.

There were no statistically significant effects on our clinical pregnancy rates for male factor presence/absence, the number of sperms in the prepared sperms for insemination, and the number of total progressive sperms. It was shown that only a sperm presence with +4 motility increased clinical pregnancy rates, which might be explained due to this study only including an unexplained and mild male subfertile patient group. Cao et al. (35) evaluated 1153 IUI cycles in 2014 and reported that a number of motile sperms lower than $2 \times 10^{6}$ in the insemination had low success rates in IUI, but the author also showed that sperm numbers higher than this is increased the observed pregnancy rates. They concluded that IUI can be performed when the NMSI (number of motile sperm inseminated) exceeds $2 \times 10^{6}$. As there was no infertile male group in our study, we showed that the number of changes in the subfertile sperm group did not affect pregnancy rates. It was further shown that the conception success rates increased only if the number of sperms with +4 motility increased. As sperm motility has a very high predictive value in an elevated chance of pregnancy, it is accepted as the major determinant of IUI success (36-39).

There are many studies in the literature related to IUI. The strength of our study in the literature is that it reviews IUI procedures that have been performed over a period of 10 years in the same clinic with the same team (one embryologist and one gynecologist).
The most important limitation of our study is that it was a retrospective trial. We evaluated data only as the gestation rate per cycle because we wanted to obtain parameters that had a predictive role only for a single cycle. However, subsequently, this design revealed some findings that were inconsistent with those in the literature, such as age and infertility duration. Further, we could have conducted an evaluation of the success rates for couples. Additionally, in our study, we did not conduct a statistical analysis on multiple gestations.

In conclusion, our study results, which are consistent with those in the literature, indicates that IUI success in secondary infertile couples who were in the unexplained infertility and mild male subfertility groups was higher than in primary infertile couples and that the chances of pregnancy increased as sperm numbers with +4 motility increased. Success in IUI is multifactorial. Synchronization of the couple and the medical team should be achieved in parallel with all other factors, such as ovaries, fallopian tubes, endometrium, cervix, vagina, and sperms. It is quite difficult to concomitantly evaluate all these parameters and to determine a predictive parameter in IUI independent from other factors. We believe that this is the possible reason for the heterogeneity of the study groups in the IUI trials in the literature. Further prospective, randomized, controlled, and well-planned clinical studies on a large scale and with high subgroup numbers are required on this subject.

Ethics Committee Approval: Ethics committee approval was received for this study from the ethics committee of Turgut Özal University School of Medicine.

Informed Consent: Written informed consent was obtained from patients who participated in this study.

Peer-review: Externally peer-reviewed.

Author Contributions: Concept - M.N.K., M.A.; Design - M.N.K., M.A.; Supervision - Z.K., S.H.; Resources - S.H., E.H.; Materials - S.H., E.H.; Data Collection and/or Processing - S.H., E.H., M.A.M., N.K.; Analysis and/or Interpretation - Z.K., Z.Kalaylığlu, M.N.K.; Literature Search M.N.K., M.A., Z.K.; Writing Manuscript - M.N.K.; Critical Review - Z.K., Z.Kalaylıoğlu; Other - M.A.

Conflict of Interest: No conflict of interest was declared by the authors.

Financial Disclosure: The authors declared that this study has received no financial support.

\section{References}

1. Romundstad LB, Opdahl S, Pinborg A. Which treatment option for couples with unexplained or mild male subfertility? BMJ 2015; 350: g7843. [Crossref]

2. National Institute for Health and Clinical Excellence (NICE) guidelines. 2013 (www.nice.org.uk)

3. Veltman-Verhulst SM, Cohlen BJ, Hughes E, Heineman MJ. Intrauterine insemination for unexplained subfertility. Cochrane Database Syst Rev 2012: CD001838. [Crossref]

4. van der Westerlaken LA, Naaktgeboren N, Helmerhorst FM. Evaluation of pregnancy rates after intrauterine insemination according to indication, age, and sperm parameters. J Assist Reprod Genet 1998; 15: 359-64. [Crossref]

5. Zadehmodarres S, Oladi B, Saeedi S, Jahed F, Ashraf H. Intrauterine insemination with husband semen: an evaluation of pregnancy rate and factors affecting outcome. J Assist Reprod Genet 2009; 26 : 7-11. [Crossref] 
6. Francavilla F, Sciarretta F, Sorgentone S, Necozione S, Santucci R, Barbonetti A, et al . Intrauterine insemination with or without mild ovarian stimulation in couples with male subfertility due to oligo/ astheno-and/or teratozoospermia or antisperm antibodies: a prospective cross-over trial. Fertil Steril 2009; 92: 1009-11. [Crossref]

7. Jeon YE, Jung JA, Kim HY, Seo SK, Cho S, Choi YS, et al. Predictive factors for pregnancy during the first four intrauterine insemination cycles using gonadotropin. Gynecol Endocrinol 2013; 29: 834-8. [Crossref]

8. Nuojua-Huttunen S, Tomas C, Bloigu R, Tuomivaara L, Martikainen $\mathrm{H}$. Intrauterine insemination treatment in subfertility: an analysis of factors affecting outcome. Hum Reprod 1999; 14: 698-703. [Crossref]

9. Steures P, van der Steeg JW, Hompes PG, Bossuyt PM, Habbema JD, Eijkemans MJ, et al; CECERM (Collaborative Effort for Clinical Evaluation in Reproductive Medicine). Effectiveness of intrauterine insemination in subfertile couples with an isolated cervical factor: a randomized clinical trial. Fertil Steril 2007; 88: 1692-6. [Crossref]

10. Practice Committee of the American Society for Reproductive Medicine. Effectiveness and treatment for unexplained infertility. Fertil Steril 2006; 86: S111-S114. [Crossref]

11. World Health Organization. WHO laboratory manual for the examination of human semen and sperm-cervical mucus interaction. Cambridge University Press 1999.

12. Kruger TF, Acosta AA, Simmons KF, Swanson RJ, Matta JF, Oehninger $\mathrm{S}$. Predictive value of abnormal sperm morphology in in vitro fertilization. Fertil Steril 1988; 49: 112-7. [Crossref]

13. Hannoun A, Abu-Musa A, Kaspar H, Khalil A. Intrauterine insemination IUI: the effect of ovarian stimulation and infertility diagnosis on pregnancy outcome. Clin Exp Obstet Gynecol 1997; 25: 144-6.

14. Guzick D, Sullivan M, Adamson GD, Cedars M, Falk R, Peterson E, et al. Efficacy of treatment for unexplained infertility. Fertil Steril 1998; 70: 207-13. [Crossref]

15. Goverde AJ, McDonnell J, Vermeiden JP, Schats R, Rutten FF, Schoemaker J. Intrauterine insemination or in-vitro fertilisation in idiopathic subfertility and male subfertility: a randomised trial and cost-effectiveness analysis. Lancet 2000; 355: 13-8. [Crossref]

16. ESHRE Capri Workshop Group. Intrauterine insemination. Hum Reprod Update 2009: 15; 265-77. [Crossref]

17. Dickey RP, Taylor SN, Lu PY, Sartor BM, Rye PH, Pyrzak R. Effect of diagnosis, age, sperm quality, and number of preovulatory follicles on the outcome of multiple cycles of clomiphene citrate-intrauterine insemination. Fertil Steril 2002; 78: 1088-95. [Crossref]

18. Tomlinson MJ, Amissah-Arthur JB, Thompson KA, Kasraie JL, Bentick B. Infertility: Prognostic indicators for intrauterine insemination (IUI): statistical model for IUI success. Hum Reprod 1996; 11: 18926. [Crossref]

19. Ibérico G, Vioque J, Ariza N, Lozano JM, Roca M, Llácer J, et al. Analysis of factors influencing pregnancy rates in homologous intrauterine insemination. Fertil Steril 2004; 81: 1308-13. [Crossref]

20. Bhattacharya S, Harrild K, Mollison J, Wordsworth S, Tay C, Harrold A, et al. Clomifene citrate or unstimulated intrauterine insemination compared with expectant management for unexplained infertility: pragmatic randomised controlled trial. BMJ 2008; 337: a716. [Crossref]

21. Guven S, Gunalp GS, Tekin Y. Factors influencing pregnancy rates in intrauterine insemination cycles. J Reprod Med 2008; 53: 257-65.

22. Hughes EG. The effectiveness of ovulation induction and intrauterine insemination in the treatment of persistent infertility: a metaanalysis. Hum Reprod 1997; 12: 1865-72. [Crossref]

23. Dorjpurev U, Kuwahara A, Yano Y, Taniguchi T, Yamamoto Y, Suto A, et al. Effect of semen characteristics on pregnancy rate following intrauterine insemination. J Med Invest 2011; 58: 127-33. [Crossref]
24. Peeraer K, Debrock S, De Loecker P, Tomassetti C, Laenen A, Welkenhuysen $\mathrm{M}$, et al. Low-dose human menopausal gonadotrophin versus clomiphene citrate in subfertile couples treated with intrauterine insemination: a randomized controlled trial. Hum Reprod 2015; 30: 1079-88. [Crossref]

25. Berker B, Kahraman K, Taskin S, Sukur YE, Sonmezer M, Atabekoglu CS. Recombinant FSH versus clomiphene citrate for ovarian stimulation in couples with unexplained infertility and male subfertility undergoing intrauterine insemination: a randomized trial. Arch Gynecol Obstet 2011; 284: 1561-6. [Crossref]

26. Costello MF. Systematic review of the treatment of ovulatory infertility with clomiphene citrate and intrauterine insemination. Aust $\mathrm{N}$ Z J Obstet Gynaecol 2004; 44: 93-102. [Crossref]

27. Dickey R, Taylor S, Curole D, Rye P. Sequential clomifene citrate and human menopausal gonadotrophin for ovulation induction: comparison to clomiphene citrate alone and human menopausal gonadotrophin alone. Hum Reprod 1993; 8: 56-9.

28. Rashidi M, Aaleyasin A, Aghahosseini M, Loloi S, Kokab A, Najmi Z. Advantages of recombinant follicle-stimulating hormone over human menopausal gonadotropin for ovarian stimulation in intrauterine insemination: a randomized clinical trial in unexplained infertility. Eur J Obstet Gynecol Reprod Biol 2013; 169: 244-7. [Crossref]

29. Demirol A, Gurgan T. Comparison of different gonadotrophin preparations in intrauterine insemination cycles for the treatment of unexplained infertility: a prospective, randomized study. Hum Reprod 2007; 22: 97-100. [Crossref]

30. Gerli S, Casini ML, Unfer V, Costabile L, Bini V, Di Renzo GC. Recombinant versus urinary follicle-stimulating hormone in intrauterine insemination cycles: a prospective, randomized analysis of cost effectiveness. Fertil Steril 2004; 82: 573-8. [Crossref]

31. Filicori M, Cognigni GE, Pocognoli P, Tabarelli C, Ferlini F, Perri T, et al. Comparison of controlled ovarian stimulation with human menopausal gonadotropin or recombinant follicle-stimulating hormone. Fertil Steril 2003: 80; 390-7. [Crossref]

32. Duran HE, Morshedi M, Kruger T, Oehninger S. Intrauterine insemination: a systematic review on determinants of success. Hum Reprod Update 2002; 8: 373-84. [Crossref]

33. van Rumste MM, den Hartog JE, Dumoulin JC, Evers JL, Land JA. Is controlled ovarian stimulation in intrauterine insemination an acceptable therapy in couples with unexplained non-conception in the perspective of multiple pregnancies? Hum Reprod 2006; 21: 701-4. [Crossref]

34. van Rumste MM, Custers IM, van der Veen F, van Wely M, Evers JL, Mol BWJ. The influence of the number of follicles on pregnancy rates in intrauterine insemination with ovarian stimulation: a metaanalysis. Hum Reprod Update 2008; 14: 563-70. [Crossref]

35. Cao S, Zhao C, Zhang J, Wu X, Zhou L, Guo X, et al. Minimum number of motile spermatozoa are required for successful fertilisation through artificial intrauterine insemination with husband's spermatozoa. Andrologia 2014; 46: 529-34. [Crossref]

36. Ombelet W, Dhont N, Thijssen A, Bosmans E, Kruger T. Semen quality and prediction of IUI success in male subfertility: a systematic review. Reprod Biomed Online 2014; 28: 300-9. [Crossref]

37. Goldman RH, Batsis M, Hacker MR, Souter I, Petrozza JC. Outcomes after intrauterine insemination are independent of provider type. Am J Obstet Gynecol 2014; 211: 492-e1. [Crossref]

38. Miller DC, Hollenbeck BK, Smith GD, Randolph JF, Christman GM, Smith YR, Ohl DA. Processed total motile sperm count correlates with pregnancy outcome after intrauterine insemination. Urology 2002; 60: 497-501. [Crossref]

39. Shulman A, Hauser R, Lipitz S, Frenkel Y, Dor J, Bider D, et al. Sperm motility is a major determinant of pregnancy outcome following intrauterine insemination. J Assist Reprod Gen 1998; 15: 381-5. [Crossref] 